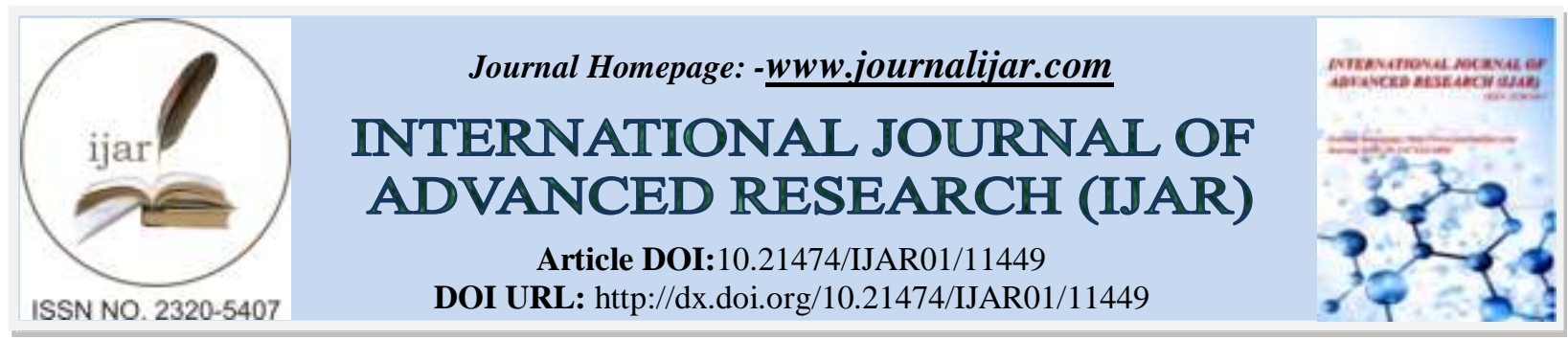

RESEARCH ARTICLE

\title{
PULMONARY FUNCTION DERANGEMENT IN PATIENTS OF DIABETES MELLITUS
}

\author{
Hemant Mahur ${ }^{1}$, Aditya C Upadhyay ${ }^{2}$, Raghavendra $\mathrm{G}^{2}$, Naveen $\mathrm{H} \mathrm{M}^{2}$ and DP Singh ${ }^{3}$ \\ 1. Professor Department of Medicine, RNT Medical College, Udaipur, Rajasthan. \\ 2. Post Graduate Resident Department of Medicine, RNT Medical College, Udaipur, Rajasthan. \\ 3. Senior Professor Department of Medicine, RNT Medical College, Udaipur, Rajasthan.
}

\section{Manuscript Info}

.........................

Manuscript History

Received: 31 May 2020

Final Accepted: 30 June 2020

Published: July 2020

\section{Abstract}

Background: Diabetes mellitus is a metabolic disorder characterized by hyperglycaemia resulting from defects in insulin secretion, action or both. Nonenzymatic glycosylation induced alteration of lung connective tissue is the most likely mechanism underlying the mechanical pulmonary dysfunction in diabetic subjects. The present study evaluates the impact of diabetes mellitus on pulmonary function in this cross sectional study of population.

Aims and objectives: To evaluate the impact of diabetes mellitus on pulmonary functions by comparing with control groups.

Materials And Method: All patients presenting in Department of Medicine, R.N.T. Medical College, Udaipur who were proved cases of type 2 diabetes mellitus were included in this study from September 2017 to September 2018. 50 patients and 50 controls with matched age and sex were included. All patients were interviewed, detailed history was taken with respect to risk factors and detailed physical examination was carried out and appropriate investigations were carried out.

Results: FVC among diabetics was low with a mean of 2.46 as compared to controls with mean of 2.99 with $p$ value of 0.001 which is statistically significant. FEV1 was reduced in cases with mean of 2.0542 compared to controls with mean of 2.4906 with a $\mathrm{p}$ value of 0.001 being statistically significant.

FEV1/ FVC was higher in diabetic group with mean value of 0.8304 as compared with controls with mean value of 0.8316 .

Conclusion: Diabetic patients show reduced lung function with a restrictive pattern of lung disease on the Spirometry.

Copy Right, IJAR, 2020,. All rights reserved.

\section{Introduction:-}

Diabetes mellitus is a metabolic disorder characterized by hyperglycemia resulting from defects in insulin secretion, action or both. Diabetes is a multisystem disorder that affects many organs of the body ${ }^{1}$.

This metabolic disorder is a risk factor precipitating micro vascular pathologies leading to autonomic neuropathy, nephropathy, retinopathy and peripheral neuropathy, and macro vascular pathologies leading to coronary artery disease, cerebrovascular accidents and peripheral vascular disease ${ }^{2}$. 
There are histopathological changes seen in lungs of diabetics such as thickened alveolar epithelial and pulmonary capillary basal lamina leading to reduced pulmonary elastic recoil and lung volume. Nonenzymatic glycosylation induced alteration of lung connective tissue is the most likely mechanism underlying the mechanical pulmonary dysfunction in diabetic subjects ${ }^{3}$.

This suggests that lung is also a target organ ${ }^{4}$. Spirometry is a widely used pulmonary function test (PFT), ideally suited to describing the effects of obstruction or restriction of lung function. The spirometric parameters have gained more popularity when it has been reported that impaired Forced Vital Capacity (FVC) and Forced Expiratory Volume in $1 \mathrm{sec}$ (FEV1) are emerging novel risk factors for diabetes mellitus ${ }^{5}$. In spite of this, spirometry is not used routinely as part of a management system in diabetic patients. Its role is neitherfully explored, nor fully utilized to achieve quality of life when managing diabetesmellitus.

The present study is undertaken to evaluate the impact of diabetes mellitus and pulmonary function in this cross sectional study of population.

\section{Materials And Method:- Inclusion Criteria:}

All patients presenting in Department of Medicine and Endocrinology at attached group of hospitals and R.N.T. Medical College, Udaipur who were proved cases of type 2 diabetes mellitus were included in this study from September 2017 to December 2018.

\section{Selection of participants:}

50 cases and 50 controls with matched age and sex were included.

\section{Exclusion Criteria:}

1. Previous history of lung disease

2. Signs and symptoms of respiratory infections at the time oftest

3. History of being admitted during past six months with respiratorysymptoms

4. History of cardiovascularillness

5. Alcoholic

6. Obesity

7. Smokers

Data were collected by using performa meeting the objectives of the study. Purpose of the study was carefully explained to patients and consent was taken.

All patients were interviewed, detailed history was taken with respect to risk factors and detailed physical examination was carried out and appropriate investigations done which included complete blood counts, fasting blood sugar, post-prandial blood sugar, $\mathrm{HbA}_{1 \mathrm{C}}, \mathrm{X}$ ray chest (PA view), Spirometry (FVC, FEV1, FEV1/FVC values recorded)

Pulmonary function tests(PFT) of diabetic patients and controls were compared by applying student's unpaired t-test while correlations between FVC, FEV1, HbA1C and duration of illness in diabetic patients were analyzed by applying Pearson's co-efficient.

\section{Results:-}

A total of 100 subjects were included in the present study 50(29 males and 21 females) of them were diabetics and the other 50(32 males and 18 females) were non diabetic controls.

$50 \%$ cases belonged to the age group of $40-49$ years, $24 \%$ to $50-59$ years and $26 \%$ to 60 and above age group. Similar distribution was assured in controls with $38 \%, 34 \%$ and $28 \%$ respectively in the three age groups. The mean age in both groups being 51.43

The glycemic parameters which included the FBS, PPBS and HbA1c are $204.86 \mathrm{mg} / \mathrm{dl}, 254.30 \mathrm{mg} / \mathrm{dl}$ and $8.1474 \%$ respectively for cases and $96.58,127.04$ and 4.802 respectively for controls.(Table I) 
Body mass index (BMI) of cases and controls were comparable with mean among study group being 24.407 and in controls its value was 25.18 . The difference was not statistically significant with a p value of 0.209 .

The spirometric values in both groups can be seen summarized in Table II. The FVC was $2.4616+0.42553$ and $2.9998+0.43302$ in cases and controls respectively while value of FEV1 was $2.0542+0.3999$ and $2.4906+0.36564$ in the same manner. Thus making the ratio of FEV1/FVC almost similar.

The study also tried to correlate the severity of impairment of the lung function test with duration of diabetes mellitus. Two groups were taken- one with disease duration $<5$ years and other $>5$ years. The glycemic parameters of the two groups are shown in Table III. It was observed that glycemic control was better in long term diabetics $>5$ years duration) than the newly diagnosed ones $(<5$ years $)$

It was also observed that the values of FEV1 and FVC were better in long term diabetics than newly diagnosed ones(Table IV) being 2.2526 against 1.9523 and 2.72377 against 2.3077 respectively.

\section{Discussion:-}

Present study was undertaken to assess ventilatory function of subjects with diabetes mellitus in comparison to subjects without diabetes. Larger population-based studies have been more consistent, demonstrating reduced pulmonary functions in patients with an elevated plasma glucose level and a diagnosis of DM.

The present study is in agreement with the previous study ${ }^{6-10}$ (Table V) and the inference drawn from this study is similar to those studies. The study proves the hypothesis of reduced FVC in diabetics compared to their age, sex and BMI matched controls.

The study also shows coherence the study of Walter E Robert et $\mathrm{al}^{11}$ who studied the relationship between diabetes mellitus and pulmonary function and showed a decrease in FVC by $109 \mathrm{ml}$ and FEV1 by $27 \mathrm{ml}$ in diabetes mellitus. Davis M.E. Timothy ${ }^{12}$ studied the pulmonary function and its association with Type-2 diabetes mellitus and showed an average decrease of $9.5 \%$ in both FVC and FEV1 of diabetics. Different studies ${ }^{6-10}$ noting the same results are compared in table VI.

Due to the combined reduction in FEV1 and FVC the FEV1/FVC ratio yielded the value of 0.83 which is suggestive of a restrictive pattern. Studies by Muhammad Irfan et al ${ }^{8}(0.819)$, $\operatorname{Sultan}^{7}(0.851)$ and Sanjeev Verma et al ${ }^{9}(0.90)$ had similar results. The present study, thus, is in agreement with previous studies which have shown almost same values of $\mathrm{FEV}_{1} / \mathrm{FVC}$ in diabetic subjects when compared to age, sex and BMI matched controls.

The key aspect of the present study is the observation that although diabetic subjects had low FVC compared to controls the group of diabetics with diabetes mellitus less than 5 years had lower FVC than in those with duration $>5$ years. FVC in diabetics with $<5$ years duration(22 study subjects) was 2.30 , much lower than controls(2.98) but in diabetics $>5$ years(28 study subjects) it was 2.70 only marginally(but significantly) less than the controls.. These results were contrary to the study done by Sultan ${ }^{7}$ where there was no significant reduction in FVC in diabetics of $<5$ years duration $(\mathrm{FVC}=3.68)$ and a linear fall in the values of $\mathrm{FVC}$ in diabetics with 5-12years duration $(\mathrm{FVC}=3.16)$ and $>12$ years duration $(\mathrm{FVC}=3.11$ ) compared to controls $(\mathrm{FVC}=3.74)$. (Figure 1 )

When the natural history of disease was compared on the time line with regard to FEV1we still observed the same improving pattern with diabetics >5years(comparison shown in table VII and figure II). While unlike FVC, FEV1 in Sultan's7 study showed similar pattern to that of ours with a decline in diabetics <5years duration and then improving in 5- 12 years duration diabetics. But Sultan's study found that beyond 12 years of duration of diabetes the FEV1 declined again. This result may have not been seen in our study due to not so long (more than 10 years) follow up of thediabetics.

Masmoudi and Zouari13 concluded that pulmonary volumes impairments are slightly more marked with diabetes mellitus duration especially after 10 years. Barret-Connor E et 14 also found that pulmonary function in older adults is altered in subjects with diabetes mellitus with duration more than 10 years. The improvement in respiratory function can be hypothesized to a better metabolic control.Our results are similar to those of Lange $\mathrm{P}^{15}$ who found that the decrease of ventilator capacity is more marked at the beginning of diabetes mellitus. Davis A Wendy et al ${ }^{16}$ who studied the glycemic exposure and associated reduced pulmonary function in type 2 diabetes found a decrease in FVC 
at an annual rate of $68 \mathrm{ml} /$ year and FEV1 at an annual rate of $71 \mathrm{ml} /$ year. This linear decline was not noticed in our study which may be the reflection of very high sugar levels at the diagnosis and eventual better control which is also reflected in asmall scale six years study by Ramiriez L.C. et al ${ }^{17}$ (1991) demonstrating that intensive treatment by subcutaneous insulin infusion improved both FVC \& FEV1 percentage predictedvalues.

Recently Nakajima et $\mathrm{al}^{18}$ reported reduced FVC and normal FEV1/FVC and concluded that impaired restrictive pulmonary function but not the obstructive pattern might be associated with metabolic disorders and metabolic syndrome in a severity dependant manner.

\section{Conclusion:-}

Lungs also bear the brunt of uncontrolled diabetes mellitus as evident by this study where mean reduction in FVC was $500 \mathrm{ml}$ and in FEV1 was $360 \mathrm{ml}$ with the parameters showing a restrictive pattern. Thus lung is also a target organ for diabetes mellitus.

\section{Limitation of the study:}

The follow up period of the patient was short and so prolonged follow up is needed to further ascertain the effects of diabetics duration on the lung functions.

\section{Future prospective:}

All diabetics can be made to get a baseline pulmonary function test using spirometry with follow up spirometries as warranted.

\section{Source of support:}

\section{none Conflict of interest:}

none

Table l:- Comparison of glycemic parameters among cases and controls.

\begin{tabular}{|l|l|l|l|l|}
\hline Variable & Group & N & Mean & S.D. \\
\hline \multirow{3}{*}{ FBS } & Cases & 50 & 204.86 & 96.58 \\
\cline { 2 - 5 } & Controls & 50 & 96.58 & 8.162 \\
\hline \multirow{2}{*}{ PPBS } & Cases & 50 & 254.30 & 46.086 \\
\cline { 2 - 5 } & Controls & 50 & 127.04 & 5.796 \\
\hline \multirow{2}{*}{ HbA1c } & Cases & 50 & 8.1474 & 0.68136 \\
\cline { 2 - 5 } & Controls & 50 & 4.8082 & 0.20983 \\
\hline
\end{tabular}

FBS - Fasting Blood Sugar, PPBS - Post Prandial Blood Sugar, HbA1c- Haemoglobin A1c N - sample size S.D.Standard Deviation

Table II:- Comparison of cases and controls with FVC, $\mathrm{FEV}_{1}$ and $\mathrm{FEV}_{1} / \mathrm{FVC}$.

\begin{tabular}{|l|l|l|l|l|l|}
\hline Variable & Group & N & Mean & S.D. & P value \\
\hline \multirow{2}{*}{ FVC } & Cases & 50 & 2.4616 & 0.42553 & $0.000^{*}$ \\
\cline { 2 - 5 } & Controls & 50 & 2.9998 & 0.43302 & \\
\hline \multirow{2}{*}{ FEV $_{1}$} & Cases & 50 & 2.0542 & 0.3999 & $0.000^{*}$ \\
\cline { 2 - 5 } & Controls & 50 & 2.4906 & 0.36564 & \\
\hline \multirow{2}{*}{ FEV $_{1} / \mathrm{FVC}$} & Cases & 50 & 0.8304 & 0.10016 & \multirow{2}{*}{0.939} \\
\cline { 2 - 5 } & Controls & 50 & 0.8316 & 0.04761 & \\
\hline
\end{tabular}

$* \mathrm{P}<0.05$

Table III:- Comparison of duration ( $<5$ yrs and $>5$ yrs) with FBS and PPBS scores in cases by t test.

\begin{tabular}{|l|l|l|l|l|l|}
\hline Variable & Duration & $\mathrm{N}$ & Mean & S.D. & P value \\
\hline FBS & $<5$ years & 22 & 214.9615 & 54.2199 & 0.2587 \\
\cline { 2 - 5 } & $>5$ years & 28 & 198.000 & 40.9376 & \\
\hline \multirow{2}{*}{ PPBS } & $<5$ years & 22 & 257.9231 & 54.7539 & 0.5697 \\
\cline { 2 - 6 } & $>$ 5 years & 28 & 249.4211 & 40.1432 & \\
\hline
\end{tabular}


Table IV:- Comparison of duration (<5 yrs and $>5$ yrs) with FVC, FEV1 and FEV1/FVC.

\begin{tabular}{|l|l|l|l|l|l|}
\hline Variable & Duration & $\mathrm{N}$ & Mean & S.D. & P value \\
\hline FVC & $<5$ years & 22 & 2.3077 & 0.4176 & $0.0010^{*}$ \\
\cline { 2 - 6 } & $>5$ years & 28 & 2.7237 & 0.3532 & $0.0129 *$ \\
\hline \multirow{2}{*}{ FEV1 } & $<5$ years & 22 & 1.9523 & 0.3744 & 0.3964 \\
\cline { 2 - 6 } & $>5$ years & 28 & 2.2526 & 0.0884 & 0.2842 \\
\hline \multirow{2}{*}{ FEV1/FVC } & $<5$ years & 22 & 0.8515 & 0.1166 & \\
\cline { 2 - 6 } & $>5$ years & 28 & 0.8184 & & \\
\hline
\end{tabular}

$* \mathrm{P}<0.05$

Table V:- Comparison of FVC with other studies among Diabetics and Controls.

\begin{tabular}{|l|l|l|}
\hline Study & Diabetics & Controls \\
\hline Klein $^{6}$ & 2.79 & 3.19 \\
\hline Sultan $^{7}$ & 3.68 & 3.74 \\
\hline Muhammad Irfan et al. $^{8}$ & 2.46 & 2.82 \\
\hline Sanjeev Verma et al. $^{9}$ & 2.12 & 2.45 \\
\hline Dharwadkar $^{10}$ & 1.74 & 1.88 \\
\hline Present study & $\mathbf{2 . 4 6}$ & $\mathbf{2 . 9 9}$ \\
\hline
\end{tabular}

Table VI:- Comparison of FEV1 with other Studies among Diabetics and Controls.

\begin{tabular}{|l|l|l|}
\hline Study & Diabetics & Controls \\
\hline Klein $^{6}$ & 2.17 & 2.49 \\
\hline Sultan & 7 & 3.13 \\
\hline Muhammad Irfan et al. $^{8}$ & 3.12 & 2.29 \\
\hline Sanjeev Verma et al. & 2.04 & 2.20 \\
\hline Dharwadkar $^{10}$ & 1.93 & 1.68 \\
\hline Present study $^{9}$ & 1.16 & 2.49 \\
\hline
\end{tabular}

Table VII:- The effect of Duration of Diabetes Mellitus on FEV 1

\begin{tabular}{|l|l|l|l|}
\hline & Duration & Diabetics & Controls \\
\hline Present study & $<5$ years $(\mathrm{n}=22)$ & 1.95 & 2.43 \\
\cline { 2 - 4 } & $>5$ years $(\mathrm{n}=28)$ & 2.25 & 2.43 \\
\hline \multirow{3}{*}{ Sultan $^{7}$} & $<5$ years $(\mathrm{n}=50)$ & 2.13 & 3.13 \\
\cline { 2 - 4 } & $5-12$ years $(\mathrm{n}=50)$ & 2.74 & 3.13 \\
\cline { 2 - 4 } & $>12$ years $(\mathrm{n}=50)$ & 2.53 & 3.13 \\
\hline
\end{tabular}

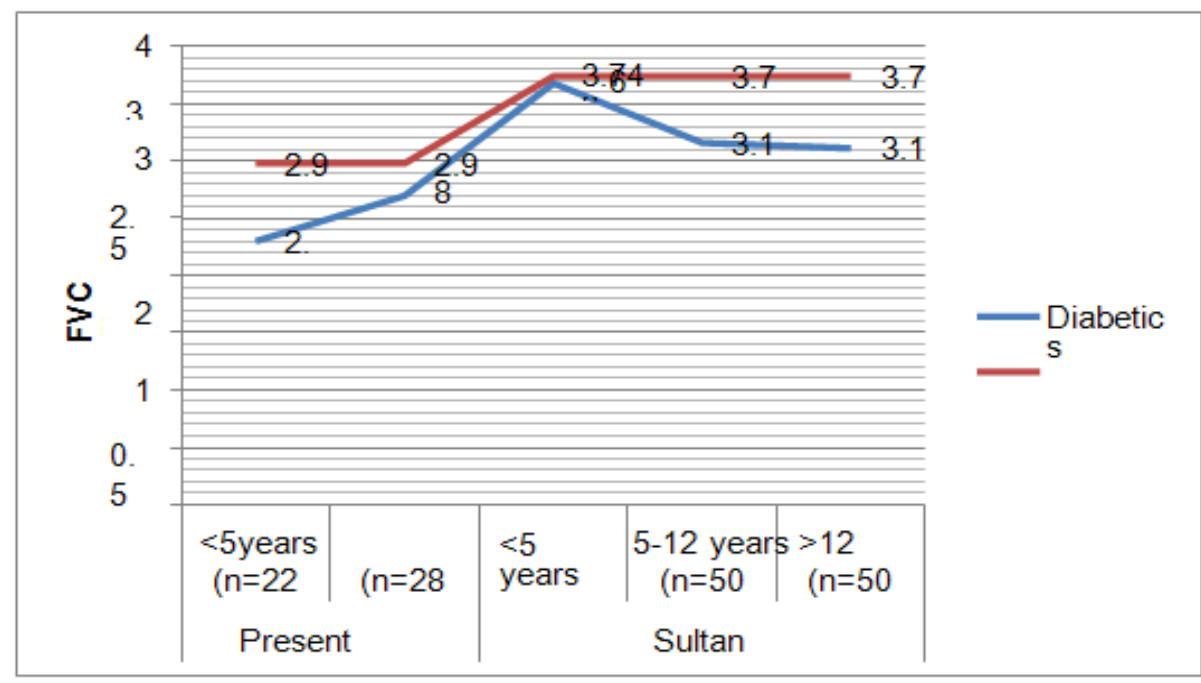

Figure I:- The effect of duration of diabetes mellitus on FVC (litres) showing comparison of our study with Sultan's. $\mathrm{n}=$ number of subjects. 


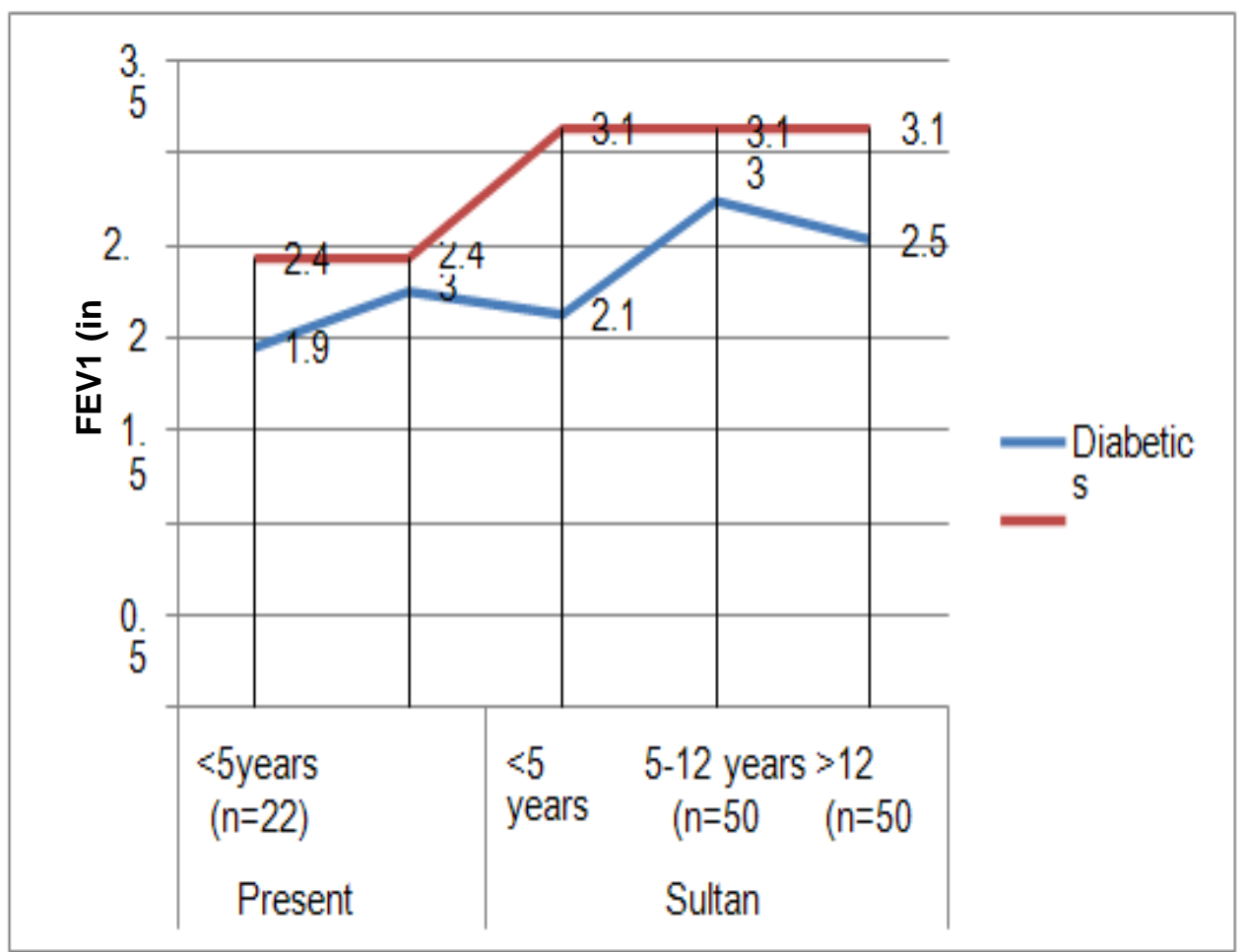

Figure II:- The effect of duration of diabetes mellitus on FEV1(litres) showing comparison of our study with Sultan's. $n=$ number of subjects.

\section{Bibliography:-}

1. Shlomo Melmed Kenneth Polonsky P. Reed Larsen Henry Kronenberg. Williams Textbook of Endocrinology 13th Edition2015

2. Benbassat CA, Stern E, Kramer M, Lebzelter J, Blum I, Fink G. Pulmonary functionsin patients with diabetes mellitus. Am J Med Sci2001;322:127-32

3. Dalquen P. The lung in diabetes mellitus. Respiration1999;66:12-3

4. Sandler Malcom. Is the lung a 'target organ' in diabetes mellitus? Arch Intern Med. 1990Jul;150(7):1385-8

5. SA, Meo. (2010). Significance of spirometry in diabetic patients. InternationalJournal of Diabetes Mellitus. 2. 47-50. 10.1016/j.ijdm.2009.12.003.

6. Klein, O. L., Kalhan, R., Williams, M. V., Tipping, M. , Lee, J. , Peng, J. and Smith,L.

7. J. (2012), Lung spirometry parameters and diffusion capacity are decreased in patients with Type 2 diabetes. Diabetic Medicine, 29: 212-219

8. Sultan Ayoub Meo. Significance of spirometry in diabetic patients International Journal of Diabetes Mellitus 2 (2010)47-50.

9. Muhammad Irfan,Abdul Jabbar, Ahmed Suleman Haque, Safia Awan, and Syed Fayyaz Hussain. Pulmonary functions in patients with diabetes mellitus. Lung India. 2011 Apr-Jun; 28(2):89-92

10. SanjeevVerma,MumtazGoni,KudyarP.Assessmentofpulmonaryfunctionsinpatientswith Diabetes Mellitus. JK science April-June 2009; vol. 11,No.2

11. Anand R. Dharwadkar, Asha A. Dharwadkar,Gouher Banu, ShrilaxmiBagali reduction in lung functions in type-2 diabetes in Indian population : correlation with glycemic status Indian J Physiol Pharmacol 2011; 55 (2) : $170-175$.

12. Walter ERobert, Alexa Beiser, Rachel J, Givelber, George T, O’Connor, et al. Association between glycemic state and lung function. Am J Respir Crit CareMed 2003;167:911-916

13. Davis Timothy M E, Matthew Knuiman, Peter Kendell, Hien Vu, Wendy A Davis. Reduced pulmonary function and its associations in type 2 diabetes: Diabetesresearch and Clinical practice 2000;50:152-159.

14. K. Masmoudi, N. Zouari, respiratory function evolution in a duration of four yearsin patients with diabetes mellitus J.I. M. Sfax, $\mathrm{N}^{\circ} 13 / 14$; Juin07/Déc07 :27-29. 
15. Barrett Connor E, Frette C. NIDDM, impaired glucose tolerance, andpulmonary function in older adults. The Rancho Bernardo Study. Diabetes Care 1996;19(12):1441-4

16. Lange P. Diabetes mellitus, plasma glucose and lung function in a cross sectional population study.Eur Respir $\mathbf{J}$ 1989:2:14-19.

17. Wendy A. Davis, Matthew Knuiman, Peter Kendall, Valerie Grange, Timothy M.E. Davis, Glycemic Exposure Is Associated With Reduced Pulmonary Function inType 2 Diabetes The Fremantle Diabetes Study 27:752$757,2004$.

18. Ramiriez LC, Dal Nogare A, Hsia C, Aruaz C, Butt I, Trowig SM, Schnurr-Breen L, Raskin P: Relationship between diabetes control and pulmonary function in insulin-dependent diabetes mellitus. Am J Med 91:371376,199

19. Nakagima K, Kubouchi Y, Muneyuki T, et al. A possible association between suspected restrictive pattern as assessed by ordinary pulmonary function test andthe metabolic syndrome. Chest 2008; 134 (4):712-18. 